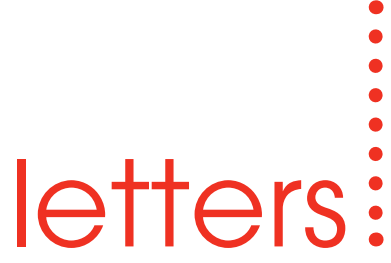

These pages offer you the chance to open topics for debate, discuss issues, or even offer advice to fellow readers. Send us your views on anything published in Vital or anything to do with working in the dental profession. We look forward to hearing from you.

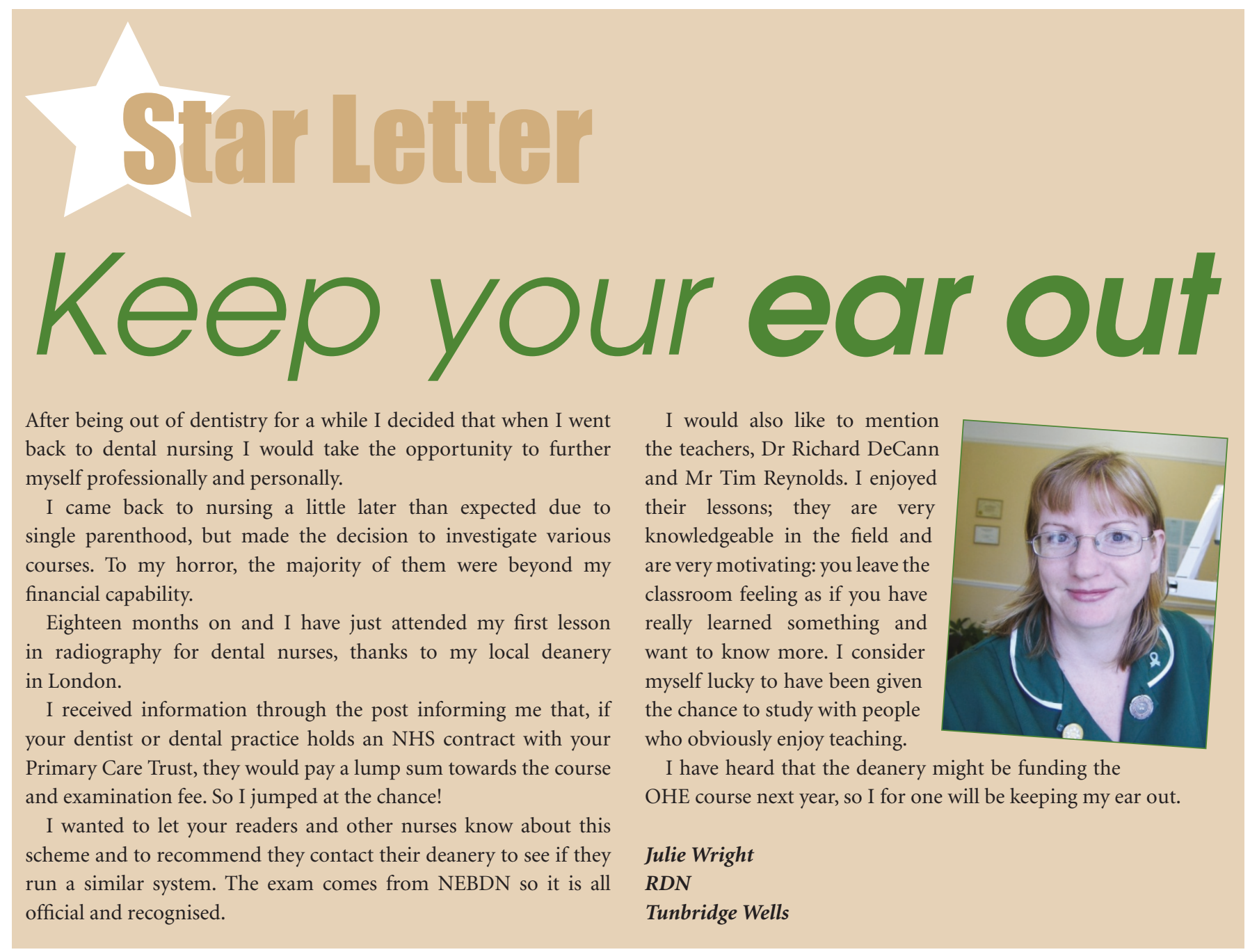

\title{
Registration long overdue
}

Vital was first brought to my attention when our Trainee Dental Nurse, Nathan Morrison, was involved and featured on the cover of the autumn 2004 issue.

I regularly read Vital and have subscribed from the early days. I am often asked questions by dental nurses (DNs) on evening courses regarding statutory registration. General dental practitioners do not seem to be clued up on this topic and where their unqualified DNs fit in. There has been some really good information on this topic in Vital. Registration is definitely a positive move in the right direction and is long overdue. I remember it being mentioned back in 1974!

Other articles in Vital have been interesting and useful as training resources. I am involved in the delivery of the NVQ Level 3 and National Examination for Dental Nurses and am pleased to see that both pathways to qualification are still up and running. Both methods should be advertised and individual
DNs may then be given the opportunity to select the one that appeals to them or at least find out what is available in their area.

\section{Liz Hooper}

Senior Dental Nurse Trainer and Appraiser By email

If you are a dental nurse and need more information on routes to registration and recognised courses, check out Registration revision on page 28. 